\title{
Erratum to: The KT Jeang Retrovirology prize 2016: Frank Kirchhoff
}

Retrovirology Editorial ${ }^{*}$

\section{Erratum to: Retrovirology (2016) 13:53 DOI 10.1186/s12977-016-0286-5}

Unfortunately, the original version of this article [1] contained an error. Figure 1 was not included. Figure 1 has

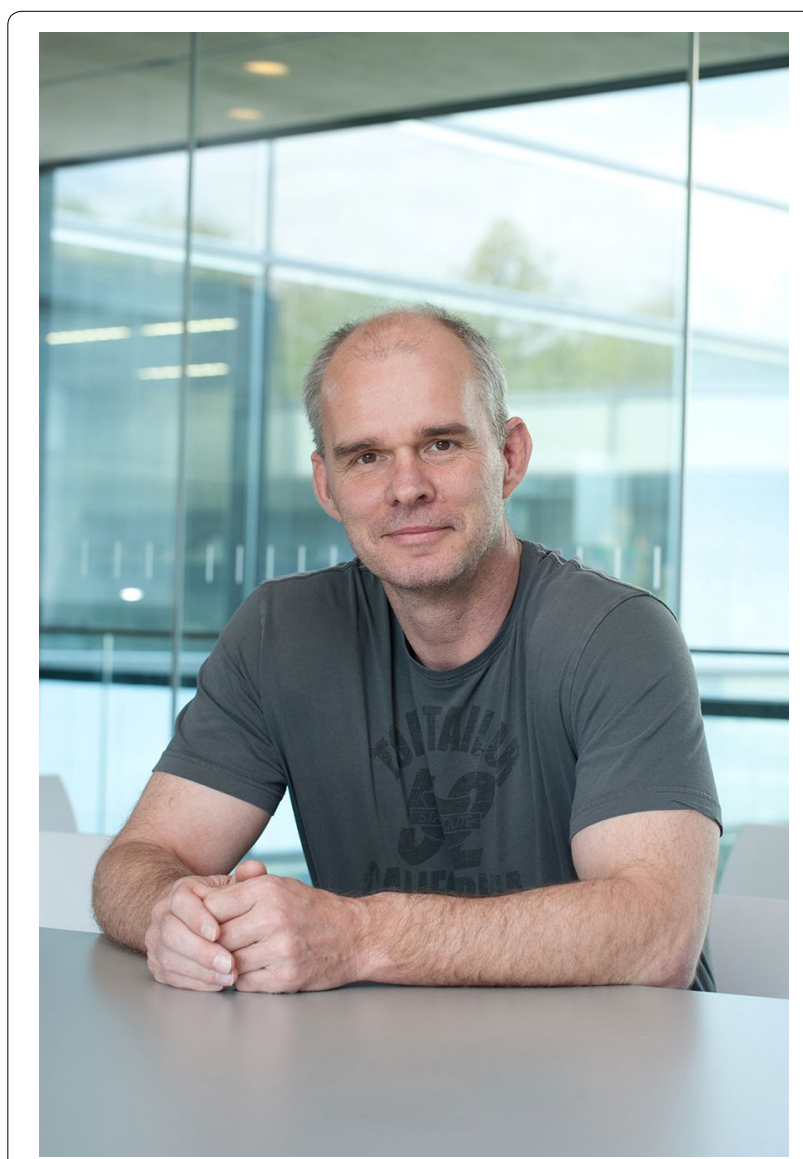

Fig. 1 Frank Kirchhoff been included in the original article and is also included correctly below.

The online version of the original article can be found under doi:10.1186/s12977-016-0286-5.

Published online: 16 September 2016

\section{Reference}

1. Retrovirology Editorial (2016) 13:53. doi:10.1186/s12977-016-0286-5.

*Correspondence: editorial@retrovirology.com

BioMed Central, 236 Gray's Inn Road, London WC1X 8HB, UK 